REVISTA DE DERECHO UNED, núm. 4, 2009

\title{
LA DEFENSA POLÍTICA DE LA CONSTITUCIÓN. CONSTITUCIÓN Y ESTADOS EXCEPCIONALES (I)
}

\author{
Juan Manuel Goig MartíneZ*
}

Resumen: La consideración de la Constitución como la Norma Suprema y Fundamental del Estado, determina que su defensa no se agote en la garantía jurídica. Junto a la defensa jurídica de la Constitución democrática es preciso su defensa política ante situaciones de anormalidad democrática al objeto de adoptar una serie de medidas tendentes a superar la crisis en la que se encuentra el Estado democrático, al objeto de que en un plazo de tiempo preciso, el propio poder democrático y los derechos y libertades queden salvaguardados. El conjunto de normas dirigidas a la defensa política de la Constitución y el disfrute de la paz cívica, constituyen el llamado Derecho de Excepción. Este Derecho de excepción, o derecho de anormalidad democrática, no es algo ajeno al Estado de Derecho, sin, o que se incluye en su propia concepción, aunque su adecuación al fenómeno democrático, y su justificación, determina la necesidad de dar una respuesta adecuada a los problemas planteados; su sometimiento a determinados principios y controles, y el cumplimiento del Derecho Internacional en materia de derechos y libertades.

Palabras clave: Constitución; Derecho de Excepción; Estados excepcionales; Derecho Internacional

Abstract: The consideration of the Constitution as the Supreme and Fundamental Norm of the State, determines that its defense does not become exhausted in the juridical guarantee. Together with the juridical defense of the democratic Constitution his its political

\footnotetext{
* Profesor Titular de Derecho Constitucional. Departamento de Derecho Político.
} 
defense must stand before situations of democratic abnormality in order to adopt a series of measures tending to overcome the crisis the democratic State is in, order to which in the space of concret time, the democratic power it self and the rights and freedoms remain safeguarded. The set of procedure directed to political defense of the Constitution and the enjoyment of the civic peace, constitute the so called Law of Exception. This Law of exception, or right of democratic abnormality, is not anything foreign to the Constitutional state, but it is included in its own conception, though its adequacy to the democratic phenomenon, and its justification, determines the need to give a response adapted to the problems raise, its submission to certain principles and controls, and the fulfillment of the International Law as for rights and freedoms.

Key words: Constitution; Law of Exception; exceptional States; International Law

Sumario: I. Introducción. La Constitución como norma y su defensa política.-II. Sobre la evolución histórica de las situaciones de excepcionalidad.-III. Sobre el concepto de estados excepcionales.-IV. Modelos en la regulación de los estados excepcionales.-V. Los estados de excepción en el derecho internacional de los derechos humanos. Especial referencia a su influencia en Latinoamérica.-VI. Defensa política de la Constitución, democracia y derechos humanos.

\section{INTRODUCCIÓN. LA CONSTITUCIÓN COMO NORMA Y SU DEFENSA POLÍTICA}

A pesar de que en etapas anteriores se otorgó a la Constitución un valor meramente programático, en la actualidad se sostiene que es una norma jurídica y como tal tiene valor normativo.

Al margen de las diversas definiciones sobre el término Constitución, podemos destacar tres aspectos del concepto: Políticamente, la Constitución es el instrumento a través del cual se articula el juego de los poderes constitucionales, los derechos y libertades del individuo y la garantía de éstos; Formalmente, la Constitución es la norma que origina todas las demás, la que determina el sometimiento de éstas a aquélla. Es la ley de leyes; Materialmente es el marco de convivencia indispensable para la vida de una comunidad.

Desde el punto de vista material, la Constitución ha sido contemplada como el modo real de ser del orden político fundamental, la 
Constitución como resultado de la evolución secular de un pueblo y no como el producto de una asamblea constituyente.

Pero junto a esta concepción material de Constitución, la doctrina ha establecido otro concepto, el concepto formal de Constitución, que, en líneas generales, define la Constitución como un documento jurídico, generalmente escrito, que articula las normas de convivencia más importantes para la comunidad, y que racionaliza la organización y actividad del poder político.

El concepto formal de Constitución se traduce en un conjunto de normas de Derecho básicas y supremas. Así la Constitución es la forma normativa de la materia normada. Conforme a la lógica jurídica, toda Constitución positiva debe ser el elemento normativo en que transcienden las potestades de autodeterminación y autolimitación de la soberanía. Es la norma suprema y fundamental que rige la vida de una nación.

La fundamentalidad denota una cualidad de la Constitución que hace que ésta sea la ley fundamental del Estado. La Constitución es el ordenamiento básico de toda la estructura jurídica estatal, es decir, el cimiento sobre el que se asienta el sistema normativo de derecho en su integridad.

Al mismo tiempo, la Constitución es Ley suprema. El principio de supremacía constitucional descansa en sólidas consideraciones lógico-jurídicas. La Constitución es la expresión normativa de las decisiones de carácter político, social, económico y cultural, así como la base misma de la estructura jurídica del Estado que sobre éstas se organiza, lo que determina la necesidad de autodefenderse frente a la actuación de los órganos que ella misma crea, y por las situaciones anormalidad constitucional.

La supremacía de la Constitución, como proyecto de racionalización del poder, determina el establecimiento de garantías constitucionales que protejan su posición de prevalencia en el ordenamiento jurídico, de manera que se imponga una sanción a aquellas normas inferiores que vulneren la Norma Suprema, bien mediante su inaplicación, bien mediante su expulsión del ordenamiento jurídico, todo ello, como ha indicado DE VEGA ${ }^{1}$ entendiendo que la creación de la Justicia constitucional como órgano de defensa de la Constitución, no se puede reducir a la defensa de la estructura y la forma de organi-

${ }^{1}$ DE VEGA GARCÍA, P., «Jurisdicción constitucional y crisis de la Constitución» en $R E P$, n. $^{\circ} 7,1979$, p. 117. 
zación en que, históricamente, cristalizó el Estado Liberal de Derecho clásico, sino que esta actividad de defensa de la Constitución implica la defensa de los valores que han inspirado el movimiento constitucionalista.

Junto a esta garantía, existe otra garantía, extraordinaria, consistente en que la reforma de la Constitución ha de hacerse mediante procedimientos excepcionales, distintos del previsto para la elaboración y aprobación de las leyes, impidiendo que el legislador pueda reformar la Constitución por los mismos procedimientos por los que se aprueba, modifica, o deroga la ley ordinaria.

Pero la necesaria confluencia de las concepciones formal y material de la Constitución, determina que las garantías de la Constitución, no se agoten en las meras garantías jurídico-estructurales. Como ha indicado CRUZ VILLALON ${ }^{2}$, la Constitución parte de una determinada concepción de la realidad social que pretende regular, y configura un proyecto en relación con una situación considerada normal, de manera que cuando la Constitución es súbitamente confrontada con una situación distinta, debe de seguir garantizando su propia eficacia. Surge así la distinción entre situaciones de normalidad y situaciones de excepción aplicado a la Constitución, y ésta tiene que saber reaccionar para salvaguardar su propia permanencia, y dar solución a las situaciones de anormalidad constitucional.

Por consiguiente, junto a la defensa jurídica de la Constitución, es precisa la «defensa política» de la misma, ante situaciones, en las que en un Estado de Derecho, es preciso una suspensión temporal de ciertos derechos y libertades, y una mayor concentración del poder político para superar la crisis que pone en peligro al Estado democrático, al objeto de que, a la larga, el propio poder democrático, y los derechos y libertades sean salvaguardados, y se disfrute de la paz cívica $^{3}$, surgiendo así lo que doctrinalmente se conoce como «Derecho de excepción».

Este derecho de excepción funcionará como una garantía de la Constitución frente a situaciones de crisis, que, sin embargo, no debe entenderse como algo ajeno al Estado de Derecho. Por el contrario, como indica ÁLVAREZ CONDE ${ }^{4}$, al ser el Estado de Derecho un mo-

${ }^{2}$ CRUZ VILLALÓN, P., Estados excepcionales y suspensión de garantías, Técnos, Madrid, 1984, p. 17

${ }^{3}$ ALZAGA VILLAMIL, O, y otros, Derecho Politico español según la Constitución española de 1978, vol. II, Madrid, CERA, 1998, p. 250.

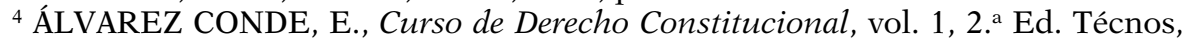
Madrid, 1996, pp. 496-497. 
delo de Estado absolutamente normalizado, que regula situaciones de normalidad, es de suponer que las situaciones de anormalidad constitucional también deben de estar normativizadas. Se trata, en definitiva, de una garantía de la Constitución que funciona como suspensión temporal de la propia Constitución.

Es necesario que se den, sin ningún género de dudas, una serie de condiciones institucionales y de principios mínimos para que podamos hablar de la existencia de un fenómeno constitucional, democrático, y que concibe la Constitución como Norma que disciplina el propio sistema constitucional del Estado ${ }^{5}$, entre los que se deben encontrar las instituciones y procedimientos de solución de conflictos y crisis constitucionales.

El presente estudio de la Defensa política de la Constitución se ceñirá al estudio del constitucionalismo democrático, puesto que en los sistemas absolutistas o totalitarios no puede, en propiedad, hablarse de estados excepcionales ni de suspensión de derechos y libertades, ya que la concentración de poder permanentemente en su detentador o detentadores llega a tales extremos, que la situación de excepción es el estado natural, y las posibles regulaciones que existan en la Constitución de los regímenes absolutistas o dictatoriales constituye un mero disfraz, o un instrumento puesto en manos del dictador o del tirano para acumular más poder ${ }^{6}$.

Por el contrario, en el Constitucionalismo democrático, la intención del constituyente al regular el derecho de excepción es el distinguir los escenarios de la normalidad y la anormalidad, dejando claro que inclusive la situación de anormalidad se sujeta al imperio de la Constitución.

Como ha indicado CRUZ VILLALÓN 7 , en la decisión del constituyente, en relación con el derecho de excepción, aparecen implicados los siguientes factores:

- En primer lugar, la adopción de un derecho de excepción, implica la decisión de hasta qué punto una Constitución puede ser suspendida temporalmente, sin que ello suponga un daño irreparable en la legitimidad misma del orden constitucional, salvando la propia Constitución.

${ }^{5}$ Vid. COLOMER VIADEL, A., Constitución, Estado y Democracia en el umbral del siglo XXI. Valencia 1995, pag 27.

${ }^{6}$ ALZAGA VILLAMIL, O., op. cit.; loc. cit.

${ }^{7}$ Op. cit. pp. 24 a 27. 
- En segundo lugar, la opción del constituyente pone de manifiesto cuales son las emergencias que tiene sentido prever.

- En tercer lugar, la opción por un determinado modelo de excepcionalidad es expresión de lo que la Constitución va a poder permitirse en relación con los institutos de excepción sin ponerse en peligro a sí misma.

- En cuarto lugar, y en sentido opuesto, el derecho de excepción y sus instituciones serán la expresión de la valoración que el constituyente haga acerca de la normalidad y estabilidad de la realidad social en la que la Constitución pretende implantarse-

- En último lugar, hay que tomar en consideración que la Constitución de normalidad y la Constitución de crisis se condicionan mutuamente, de manera que ante situaciones excepcionales no puede alegarse falta de regulación, y habrá que actuar de acuerdo con los mandatos establecidos constitucionalmente.

En definitiva, la respuesta que el constituyente democrático ofrece a la situación de anormalidad es jurídica, aunque su estructura, naturaleza y limitaciones revistan una particularidad que se explica por el fenómeno al cual se remite.

\section{SOBRE LA EVOLUCIÓN HISTÓRICA DE LAS SITUACIONES DE EXCEPCIONALIDAD}

Por razones de lógica política y experiencia práctica, el estudio de los estados excepcionales ha preocupado a la teoría política desde sus comienzos, en particular desde la aparición del Estado moderno.

Los estados de excepción han tenido una evolución histórica paulatina desde la dictadura de la república romana hasta la fecha.

La teoría política clásica ha señalado como uno de los orígenes de los estados excepcionales, la figura romana del dictador, que ejercía poderes casi ilimitados durante un lapso que el Senado considerara suficiente para superar el estado de necesidad o calamidad, que motivaba la solicitud a un ciudadano notable para que asumiera tal magistatura, aunque no podía modificar las leyes fundamentales, puesto que no ejercía un poder soberano originario sino uno delegado por el Senado.

En efecto, la creación de disposiciones jurídicas para regular las situaciones graves de conflictos internos o externos surgieron en for- 
ma definida en el derecho romano, en cuanto se establecieron normas de duración temporal con el fin de que las autoridades públicas pudiesen superar las situaciones de peligro derivadas de insurrecciones internas o de guerra exterior. Durante la República se estableció la dictadura comisarial, que consistía en la designación por el cónsul a solicitud del Senado, de un funcionario durante un periodo de seis meses con atribuciones para hacer frente a la emergencia, pero en la práctica, si la situación se normalizaba antes de concluir dicho plazo, el comisario debía dejar su cargo. Se distingue esta dictadura temporal (comisarial) de la permanente (soberana), que se transformaba en tiranía, como las ejercidas por Sila y por César.

También en la búsqueda de los orígenes del estado de excepción se ha analizado la institución romana del iustitium. Desde su etimología, bastante segura, de «ius-stare», es decir, «la suspensión del derecho", se explica su eventual intervención en casos de peligro para la República ${ }^{8}$. En estas circunstancias se decretaba el tumultus (situación de emergencia ocasionada por una guerra exterior, una insurrección o una guerra civil), un acto complementario a la suspensión temporal de las garantías constitucionales por medio de la promulgación del senatus consultum ultimum (como una situación que se ubica fuera del ordenamiento, pero que se justifica por la legítima defensa que el Estado puede realizar en protección propia y de cada uno de los ciudadanos). Por la declaración de iustitium no procedía la declaración de un imperium dictatorial especial a favor del magistrado, sino una suspensión de las leyes limitativas de sus acciones. De ahí que la situación no sea llamada «dictadura» sino «cuasi dictadura»; sin embargo, el iustitium, era más fácil identificarlo con la plenitud de poderes del dictator, que a un vacío y una detención del derecho.

Durante la etapa que se ha calificado como Antiguo Régimen, durante la existencia de los regímenes absolutistas de la Europa continental, y en cierta medida también en Inglaterra, las situaciones de emergencia no se regulaban de manera precisa, y especialmente tratándose de los conflictos internos en los cuales predominaban los motines, sobre todo en momentos de escasez de alimentos, estos disturbios se reprimían de manera pragmática, castigar duramente a los más conspicuos y perdonar a los demás. Las situaciones de emergencia tenían un carácter predominantemente preventivo más que re-

\footnotetext{
${ }^{8}$ AGAMBEN, G., Estado de Excepción (homo sacer II, 1) (trad. Antonio Gimeno Cuspinera, Pre-Textos, Valencia, octubre 2004, pp. 63-64.
} 
presivo, ya que se tomaban medidas, como el suministro de alimentos cuando los mismos escaseaban, para evitar hasta donde era posible las revueltas.

Como ha indicado ÁLVAREZ CONDE ${ }^{9}$, tampoco el Estado Liberal, en un principio, prestó especial interés en adoptar medidas excepcionales, sin embargo, las primeras crisis que a medados del S. XIX, tuvo que experimentar el Estado Liberal dieron lugar a la modificación de la conciencia política en la medida de adaptar la realidad jurídico-normativa a la realidad social, evitando rupturas constitucionales, adoptando las medidas de excepción como garantía constitucional. ${ }^{10}$

Con el surgimiento del constitucionalismo clásico, que se inicia con la lucha de independencia en los Estados Unidos de América y la revolución francesa en el continente, se desmantelan los procedimientos preventivos del antiguo régimen y comienza una nueva etapa con el establecimiento del concepto del orden público constitucional como opuesto al del sistema absolutista del antiguo régimen, que se caracterizaba por ser: esencialmente represiva frente a las prácticas preventivas anteriores; legal en lugar de arbitraria, y finalmente efectiva respecto de la ineficacia frecuente del régimen autocrático anterior. En los primeros textos fundamentales modernos, se introdujeron las facultades de emergencia, con lo cual se constitucionalizan las declaraciones de los estados de excepción, que posteriormente se desarrollaron en la legislación, para hacer frente a las insurrecciones internas y a las amenazas externas.

La transición entre la Primera República francesa y el régimen de Napoleón es un ejemplo clásico de evolución en un sentido seudorevolucionario. El estudio histórico del derecho de excepción, nos permitiría situarlo en la Francia de la revolución, concretamente en un Decreto de la Asamblea Constituyente de 8 de julio de 1791, aunque su forma como «estado de sitio ficticio o político habría quedado definida más tarde, tanto por una ley del Directorio, del 27 de agosto de 1797, como por un decreto de Napoleón de 24 de diciembre de 1811, aunque un paso más adelante se da con la in-

${ }^{9}$ Op. cit., loc. cit.

${ }^{10}$ No obstante, la institución de suspensión excepcional de derechos se puede observar en la figura de la Martial law, inglesa, como derecho derivado del Common Law, mediante cuya aplicación, la Corona y los ciudadanos podrían repeler por la fuerza cualquier insurrección a la ley, al objeto de defender la paz. Vid. REMOTTI CARBONEL, JC., «El derecho de derogación», en GÓMEZ SÁNCHEZ, Y. (coorda.), Los derechos en Europa, Madrid, UNED, 2001. 
clusión en la «Chartre» de 1814, del artículo 14 que autorizaba al soberano a elaborar reglamentos y ordenanzas necesarios para la seguridad del Estado ${ }^{11}$.

Entre las dos guerras mundiales, la teoría del estado de excepción conoció un momento de especial fortuna bajo el debate sobre la dictadura constitucional, cuyo estudio y teorización había iniciado CARL SCHMITT en $1891^{12}$. La proclamación de una dictadura proteccionista para hacer frente a situaciones de crisis determinó prácticamente el desarrollo posterior en Italia (Mussolini), Polonia (Pilsudski), Turquía (Kemal Atakürk), España (Primo de Rivera y Franco), Portugal (Salazar), Alemania (Papen y Hitler), Austria (Dollfuss y Schuschnigg), y en los Países balcánicos; en América del Sur tales procesos pertenecían a la política cotidiana.

En Alemania, la llegada de Hitler al poder fue un claro resultado del uso y abuso de los poderes de emergencia otorgados al Presidente de la República de Weimar. De acuerdo con el artículo 48 de la Constitución, el Presidente tenía derecho a sustituir la legislación parlamentaria normal por «decretos de excepción» y a emplear la fuerza militar para llevar a cabo la ejecución en cada Estado, de dichos decretos federales. En 1923, con un presidente democrático (Ebert), este poder fue utilizado estrictamente como una medida temporal para la protección de la República; después de 1930, bajo Hindenburg, se institucionalizó gradualmente el régimen de excepción paralizando sucesivas disoluciones del Reichstag el control parlamentario. Fue precisamente en tal momento cuando las fuerzas antidemocráticas de derechas lograron liquidar al gobierno constitucional. La dictadura nazi comenzó con la legalidad que rodeaba al gobierno de excepción, antes de que Hitler terminara por neutralizar al parlamento y suprimir los grupos no nazis, que hasta las últimas elecciones (marzo 1933) disponían de la mayoría de los votos.

\section{SOBRE EL CONCEPTO DE ESTADOS EXCEPCIONALES}

La posibilidad de que se produzcan acontecimientos extraordinarios que, de alguna forma, entrañen una seria perturbación de la

\footnotetext{
${ }^{11}$ AGAMBEN, G., Estado de Excepción (homo sacer II, 1), op. cit., pp. 23-38

12 Vid. SCHMITT, C., La dittadura. Dalle origini dell'idea moderna si sovranitá alla lotta di clasees proletaria, Bari, Laterza, 1975.
} 
normalidad constitucional obliga a formular las oportunas previsiones normativas con las que enfrentar la sobrevenida situación de crisis. A este conjunto de normas jurídicas, se le denomina, doctrinalmente, «Derecho de excepción».

En la base de las justificaciones jurídicas de los estados de excepción se encuentra un brocardo tomado del Decretum Gratiani ${ }^{13}$ : «necessitas legem non habet». La proposición, que literalmente significa que «la necesidad no tiene ley», puede entenderse en dos sentidos: «la necesidad no reconoce ley alguna»; y, "la necesidad crea su propia ley». El primero de los significados es el original, pero en la actualidad el segundo de los significados es el dominante. De ahí que desde Jellinek a Duguit, pasando por el pensamiento extremo de Santi Romano, se vea en la «necesidad» el fundamento de la validez de los decretos con fuerza de ley promulgados por el Ejecutivo durante el estado de excepción. Así, el estado de excepción, como expresión de la necesidad, se presenta desde sus orígenes, junto con la revolución y la instauración de hecho de un ordenamiento constitucional, como «una medida ilegal pero perfectamente jurídica y constitucional que se concreta en la producción de nuevas normas (o de un nuevo orden jurídico)». La excepción, la necesidad y la emergencia en la defensa del orden legalmente instaurado, constituyen, con carácter general, la justificación del «Derecho de urgencia».

$\mathrm{Al}$ referirnos a los Estados de Excepción, es preciso diferenciar los sentidos que tiene esta denominación. En sentido amplio, se refiere a la contravención, total y absoluta, del Estado de Derecho usualmente por los gobiernos de facto. En sentido restringido, es la modificación de determinados mecanismos del Estado de Derecho para su defensa ante situaciones anormales ${ }^{14}$, siendo el sentido restringido de la expresión el que a nosotros nos interesa.

Existen dos posiciones en la doctrina para definir los Estados de Excepción: una primera, que totaliza en estos términos todas las situaciones en las cuales se modifican algunos mecanismos del Estado de Derecho ${ }^{15}$; y la segunda, que restringe la definición a lo que se co-

${ }^{13}$ AGAMBEN, G., Estado de Excepción (homo sacer II, 1), op. cit., pp. 43-44.

${ }^{14}$ GARCÍA BELAÚNDE, D., Teoría y Practica de la Constitución peruana. Tomo I. Editorial y Distribuidora de Libros S.A. Lima. 1989, pp. 357-359.

${ }^{15}$ LOEWENSTEIN, K., Teoría de la Constitución. Reimpresión de la segunda edición en Español de 1965. Editorial Ariel S.A., Barcelona., 1982, p. 285; Ferrero R., Ciencia Política. Teoría del Estado y Derecho Constitucional. Editorial Ausonia Talleres Gráficos S.A., Lima.1984, pp. 380-381. 
noce como la suspensión de derechos o suspensión de garantías ante una emergencia que afecta el orden político o social ${ }^{16}$.

La literatura jurídica define a los estados de excepción como una institución de carácter constitucional o legal que entra en vigor como consecuencia de la aparición de circunstancias excepcionales, conjuntamente con una normativa especial que sustituye de forma parcial y con carácter temporal a la normativa ordinaria, y que emana de la necesidad de autoconservación, y se legitima porque existe para la protección y la salvaguarda del orden existente en la sociedad, aunque durante la vigencia de los estados excepcionales existe la posibilidad que se atente contra el Estado de Derecho, debido a las medidas no ordinarias tomadas para hacerle frente a los hechos imprevistos, pero, en realidad, la emergencia no comporta el tránsito de un Estado de Derecho a un Estado de poder, sino la adecuación del Derecho a una situación excepcional. Es decir, el Derecho de excepción no debe entenderse como algo extraño al Estado de Derecho, sino como un mecanismo de carácter extraordinario que se necesita para su defensa. En esta misma línea de aceptar, como algo natural, la previsión por la Constitución de una defensa extraordinaria de su propia permanencia, las normas del «Derecho de excepción» ni siquiera tienen carácter excepcional, toda vez que son las normas constitucionalmente previstas para ser aplicadas en el caso de que se den las circunstancias extraordinarias que pongan en peligro la subsistencia de la Constitución. Se trataría, pues, de una aplicación preferente, basada en el principio de "lex specialis», de esta normativa extraordinaria frente a la normativa ordinaria que rige en circunstancias normales, criterio asumido por la mayoría de constitucionalistas españoles ${ }^{17}$.

En ese sentido, si el Estado de Derecho implica que el Estado debe actuar con base en las previsiones generales contenidas en las normas escritas, es lógico que las repuestas deban ser acordes con el sentido y razón del Estado de Derecho. Como ha indicado GARCÍA

${ }^{16}$ DURÁN DÍAZ, E., «Los Derechos Humanos en Estados de Excepción: Los Derechos Humanos y la Dignidad Humana», Los estados de emergencia en la región andina. GARCÍA SAYÁN, D (Editor). Comisión Andina de Juristas, Lima. 1987 pp. 61-92.

17 Vid., por todos, CRUZ VILLALÓN, P, Estados excepcionales y suspensión de garantías, Madrid 1984, 13-23; y FERNÁNDEZ SEGADO, F., El estado de excepción en el Derecho Constitucional español, Madrid 1977, 14-24. Vid. también de este último autor, La Ley Orgánica de los estados de alarma, excepción y sitio, en Revista de Derecho Politico, UNED núm. 11, 83 ss. y SCHMITT, C en su Teoría de la Constitución (trad. esp., Madrid 1982, 124-126). 
PELAYO, «el Estado de Derecho lleva en su propia dialéctica la necesidad de un derecho excepcional, es decir, de prever la excepción y de normativizar la misma excepción» ${ }^{18}$.

El concepto de estado de excepción se basa en el supuesto de que, en algunas situaciones de emergencia política, militar o económica, el régimen de limitación y equilibrio de poderes, propio de las reglas de juego constitucionales, tenga que dejar vía libre a un poder ejecutivo más fuerte, e incluso al ejército.

Así, el derecho de excepción lo podemos definir como el conjunto normativo que regula el ejercicio del Poder Público durante la existencia de circunstancias extraordinarias, que permiten al Estado hacerle frente, y que implican un cambio en las reglas que se aplican en tiempo de normalidad, que se refleja, esencialmente, en una ampliación del poder normativo del Ejecutivo Nacional y en la posibilidad de afectar, en cierta medida, la obligación que tiene el Estado de garantizar el ejercicio y disfrute de los derechos humanos.

Las Constituciones, con carácter general, contienen un conjunto de reglas, normas o preceptos aplicables a situaciones de anormalidad social del Estado. El problema de la emergencia radica en que supone una alteración del sistema institucional establecido que implica, sin lugar a dudas, importantes consecuencias en relación con el reparto de poder y con la protección y tutela de los derechos fundamentales, por ello, y aunque posteriormente será desarrollado con mayor amplitud, para la plena validez jurídica de esa emergencia, se debe exigir, al menos, la concurrencia de tres requisitos: la extrema gravedad de la situación de riesgo para la Constitución; el respeto a la normativa constitucional; y, la proporcionalidad de las medidas a adoptar en relación con la finalidad perseguida de defensa constitucional.

En el derecho comparado los estados de excepción presentan elementos comunes. La distinción entre un régimen de excepción y otro radica, fundamentalmente, en la modalidad en que se dan estos elementos.

\section{Situación de excepción}

La situación de excepción o situación extraordinaria es toda alteración del normal desenvolvimiento de la sociedad, cuya gravedad

${ }^{18}$ GARCÍA PELAYO, M., Derecho Constitucional Comparado, Caracas: Ex Libris, 2005, p. 163. 
hace necesaria la adopción de medidas excepcionales. Estas situaciones son imprevisibles, pues aún sabiendo cuales son, no se puede determinar cuando ocurrirán.

Las situaciones de excepción más corrientes son ${ }^{19}$ :

- Guerra o conflicto internacional; empleo de la violencia física (militar) por fuerzas organizadas de una nación contra otra.

- Alteraciones o desórdenes internos; categoría en cuya amplitud se encuentran abarcadas, desde las situaciones de conflictos armados no internacionales (guerra civil), hasta fenómenos naturales graves (catástrofes), y se circunscriben al territorio o jurisdicción de un solo Estado.

- Emergencias económicas; son los desajustes de la economía de una nación cuya posibilidad se encuentra tanto en las economías centrales, como periféricas, en cuya regulación viene impuesta, porque las estructuras de subdesarrollo de los Estados, hacen muy vulnerables a las sociedad frente a esta situación.

\section{Formalidad de Excepción}

Es el procedimiento que, conforme a la Constitución y las leyes, utiliza el órgano o los órganos del Estado para asumir las situaciones de excepción. Puede variar desde la simple declaración hasta la aprobación de normas legales y administrativas.

\section{Medidas de Excepción}

Son las acciones e instrumentos que asume el Estado para hacer frente a la situación excepcional. Estos instrumentos pueden ser la alteración de principios o la adopción de nuevos mecanismos del Estado de Derecho.

Podemos distinguir entre la formalidad de excepción y las medidas de excepción, en cuanto la primera es la adopción de instrumentos o mecanismos y las segundas son los instrumentos o mecanismos adoptados.

${ }^{19}$ Vid. BIDART CAMPOS G., «La doctrina de la emergencia y las situaciones de excepción», en: BLANCAS, C Y RUBIO, M. (Compiladores)., Derecho Constitucional General. Pontificia Universidad Católica del Perú, Fondo Editorial. Lima., 1986, pp. 582 y ss. 
Pero también la regulación de la excepción plantea importantes problemas, que podrían resumirse en cinco preguntas ${ }^{20}$ :

1. ¿Quién será competente para declarar la situación de emergencia, o la necesidad de un estado de excepción?. Generalmente, se suele atribuir esta función al ejecutivo, aunque se hace preciso salvaguardar las funciones del Parlamento.

2. ¿Cuándo surge el estado de excepción, y cómo puede definirse? Aun cuando existen diversas situaciones bajo las cuales pueden declararse los distintos estados excepcionales, planteamientos democráticos exigirán la suficiente concreción y definición, al objeto de evitar el abuso de poder.

3. ¿Qué significa en realidad el estado de excepción? Habría que distinguir entre una concentración de funciones, acompañada de cierta simplificación del proceso político en el marco de un sistema responsable de gobierno, que respete las competencias de las cámaras legislativas y de los tribunales, por un lado; y el concepto de una dictadura temporal que, suspendiendo el régimen democrático y el imperio del Derecho, está orientada a capacitar al ejecutivo para legislar por derecho propio, por otro.

4. ¿Qué controles deben conservarse y cuáles deben introducirse para reducir los peligros inherentes a cualquiera de estas soluciones? Si el estado de excepción significa simplemente un fortalecimiento del gobierno democrático, los controles que el propio sistema democrático regula pueden ser válidos. Sin embargo, cualquier cambio importante de funciones entre el legislativo y los órganos del ejecutivo, aunque solo sea por un periodo limitado, requiere controles especiales para hacer frente a los riesgos y peligros de un gobierno de concentración excesiva de poder

5. ¿Cómo termina un estado de excepción? Aun cuando el final del estado de excepción depende de la situación de excepcionalidad, es deseable una duración limitada.

Junto a los elementos y a las formalidades necesarias para la declaración de los Estados excepcionales, la doctrina ${ }^{21}$ también ha distinguido la necesaria existencia de unos límites, que deberían estar

${ }^{20}$ DIETRICH BRACHER, K., «Estado de Excepción», Enciclopedia Internacional de las Ciencias Sociales, Madrid, pp. 473-476.

${ }^{21}$ ÁLVAREZ CONDE, E., op. cit., p. 498. 
presentes en todo derecho de excepción que se precie de serlo en un Estado democrático:

- El respeto a la organización e independencia de los Tribunales.

- El sometimiento al principio de constitucionalidad y legalidad.

- El establecimiento expreso de la imposibilidad de reforma de la Constitución.

- La existencia constatada de una alteración grave e inmediata para la vida del Estado.

- Que la finalidad del derecho de excepción no sólo garantice la superación de la crisis, sino la vuelta a la normalidad constitucional.

- Estos límites deben resumirse en uno principal: que el ámbito de las instituciones de la anormalidad, se reserve para aquellas perturbaciones que puedan poner en peligro elementos y condiciones esenciales del sistema económico, político, social o del medio ambiente, más allá de lo que resulte ser en un momento dado su rango normal de existencia o funcionamiento y que tenga la posibilidad de amenazar con superar el límite crítico. La función de los gobernantes es la de crear condiciones para vivir en la normalidad y controlar que las tensiones no rebasen los márgenes normales, actuando en todo caso cuando todavía se dispone de una capacidad de respuesta antes de que una de ellas llegue al punto crítico y la sociedad y sus instituciones se expongan al colapso.

De la conceptualización del Derecho de excepción democrático que se define por la normalidad, y, en términos teleológicos, como dispositivo institucional para retornar a dicha normalidad, y su combinación con sus elementos, y límites, se pueden extraer una serie de principios que deben de regir en su regulación:

1.1. Principio de taxatividad o numerus clausus de circunstancias extraordinarias. Las alteraciones de la normalidad que constituyen el régimen de excepción, son únicamente las previstas en la Constitución, o en las leyes, y, en la medida de lo posible, deben de ser lo más concretas posibles.

1.2. Principio de formalidad. El ingreso a la anormalidad y la superación de esta situación, se producen en virtud de una declaración, que deberá hacerse con las formalidades establecidas en las normas reguladoras. 
1.3. Principio de proporcionalidad. El uso de los poderes excepcionales debe comportar el mínimo sacrificio posible, compatible con la situación extraordinaria y la necesidad de conjurarla, del régimen constitucional ordinario. Por consiguiente: no podrán suspenderse los derechos humanos ni las libertades fundamentales más allá de lo permitido constitucionalmente; no se interrumpirá el normal funcionamiento de las ramas del poder público; el ejercicio de las facultades será sólo el necesario para enfrentar eficazmente la anormalidad; las medidas deben ser proporcionales a la gravedad de los hechos;la duración de los estados está temporalmente definida, y los órganos que asuman las facultades de excepción, responderán por los abusos que cometan al hacer uso de las facultades excepcionales.

1.4. Principio democrático. Durante los estados de excepción, el Legislativo debe conservar la plenitud de sus funciones normativas y de control. Si bien la técnica que sustenta la legitimidad democrática se invierte, la misma se reconstituye con posterioridad con ocasión del control constitucional y político.

1.5. Principio de control. Durante la vigencia de los estados excepcionales, el mantenimiento de sistemas de control es elemento imprescindible para el aseguramiento de que las medidas y los poderes de excepción se van a mover dentro de los cauces constitucionales y legislativos que los marcan, por ello, es imprescindible que los controles se mantengan, incluso se potencien, en toda su magnitud. A estos efectos, deberá establecerse:

- Control político. Los estados de excepción no interrumpen el funcionamiento del Congreso, el cual debe conservar la plenitud de sus atribuciones constitucionales.

- Control judicial, dentro del cual habría que distinguir entre:

A) Control constitucional de los decretos o actos que declaran un estado de excepción: Además del control formal - referido a la concurrencia de ciertos requisitos que exige la Constitución: existencia de motivación; período de duración, es preciso que se establezcan mecanismos del control material de los decretos mediante los cuales se declaran los estados de excepción. 
El control integral es el único que asegura la primacía de la Constitución como norma de normas, siendo a los órganos de la Jurisdicción constitucional a quienes les corresponde la guarda de la «integridad» y de la «supremacía» de la Constitución.

B) Control constitucional de los decretos o actos dictados en desarrollo de los estados de excepción: Los órganos correspondientes deben de realizar un examen constitucional integral de las normas legislativas dictadas durante la emergencia. Se confronta cada decreto con el universo de las normas constitucionales.

Entre otros aspectos, el examen constitucional se ocupa de verificar, en primer término, la relación de causalidad y conexión de la medida con la situación específica que hubiere determinado el estado de excepción, relación que debe ser «directa y específica», y en segundo término, se toma en consideración la "proporcionalidad» de las medidas con referencia a la gravedad de los hechos.

Sin embargo, la justificación principal del control constitucional, está dado por la protección de los derechos frente a la expansión de los poderes excepcionales y al uso que se haga de los mismos.

1.6. Principio de máxima certeza y seguridad. La determinación de los supuestos de hecho configuradores de los estados de excepción no deberán reflejar ningún poder discrecional. Aunque los hechos que integran las causas de los estados de excepción se formulan en la Constitución mediante fórmulas o conceptos jurídicos indeterminados —grave perturbación del orden público, amenaza a la estabilidad institucional, grave daño a la convivencia ciudadana etc.- - deben de ser determinables. En este sentido, se le debe reconocer a las autoridades competentes un margen necesario de apreciación e interpretación de la realidad subyacente, pese a que no puede ignorar la existencia real de los hechos que dan base a sus calificaciones, ni sustraerse a un escrutinio lógico y racional del nexo de probabilidad que pueda enlazarse a sus manifestaciones y previsiones, así como de la misma congruencia de su argumentación a la luz de las circunstancias cuya existencia se proclama». En suma, el juicio que los órganos autorizados a la declaración de las situaciones de anormalidad debe ser de naturaleza cognoscitiva e interpretativa, por 
no estar referido a la oportunidad o conveniencia, sino a la existencia o inexistencia de los hechos que constituyen el presupuesto objetivo de los estados de excepción.

\section{MODELOS EN LA REGULACIÓN DE LOS ESTADOS EXCEPCIONALES}

La tendencia general en el estudio de los distintos modelos de regulación de los Estados Excepcionales, es la existencia de previsiones de la emergencia en los ordenamientos constitucionales de los Estados, como mecanismos necesarios para la propia defensa del orden constitucional y de los derechos fundamentales, y esta tendencia en el establecimiento de garantías en el ámbito de los ordenamientos constitucionales suele estar orientada a prever órganos y medidas de protección, junto a un posterior desarrollo legislativo, si bien también existen supuestos de ausencia de previsión constitucional directa, lo que acentúa el problema. Ello ha llevado a algún sector a distinguir entre «emergencia anticipada» cuando está contenida previamente en un instrumento jurídico, y «necesidad de intervención» para afrontar situaciones de emergencia cuando no existen fuentes para cubrir dicha necesidad ${ }^{22}$.

Por consiguiente, dentro del estudio del Derecho Comparado, se utilizan tres modelos de estados de excepción. El primero consiste en la ausencia total de estados de excepción, es decir, no se prevé la posibilidad de suspender la Constitución. El segundo modelo se caracteriza por la existencia de estados de excepción a través de los cuales el Estado puede suspender la vigencia de la Constitución de manera temporal y en los casos taxativamente enunciados y una vez sea superada la crisis, restablecer el orden. Y por último, «la dictadura constitucional», que es mucho más amplia frente a las medidas que puede adoptar el ejecutivo, modelo que adoptó Francia en su Constitución de 1958 y que recientemente fue propuesto por el actual Procurador General de la Nación para ser impuesto en Colombia.

Aunque el modelo general es el reconocimiento constitucional del derecho de excepción, existen supuestos de falta o carencia del mismo, como opción del constituyente de considerar que la Constitución, como instrumento supremo de ordenación de la vida de un

${ }^{22}$ DOMÍNGUEZ ZORRERO, M., «Estados excepcionales y garantía de derechos fundamentales en Latinoamérica», REP, n. ${ }^{\circ}$ 81, 1993, p. 266. 
Estado, no puede ser alterada o suspendida ${ }^{23}$, siendo el ejemplo más citado, la Constitución Belga de 1831, cuyo art. 130 establecía la prohibición de suspender, en todo o en parte, la Constitución, pero también podemos citar la Constitución belga de 1994 (art. 187), o el artículo 113, de la Constitución de Luxemburgo. También en el ordenamiento italiano, la Constitución contempla la emergencia internacional pero no los supuestos de emergencia internos en el seno del propio Estado, en la idea de que la fijación de instrumentos y medidas en la propia Constitución se podría utilizar por el Gobierno para la limitación de derechos. Esta falta de regulación constitucional directa ha dado lugar a que el sistema de excepción italiano sea fruto de un posterior desarrollo legislativo y de la labor de control de la Corte Constitucional italiana ${ }^{24}$.

El art. 1. ${ }^{\circ}$, del Título VIII de la Constitución francesa de 1791, primera Constitución que contiene previsiones de emergencia o de situaciones de excepcionalidad, inaugura la tendencia a prevenir la anormalidad constitucional directamente en los textos constitucionales.

Como ha indicado CRUZ VILLALÓN ${ }^{25}$, dentro de los ordenamientos que contienen un derecho de excepción estrictamente reconocido, existen dos modelos básicos: el Estado excepcional y la dictadura constitucional.

La dictadura constitucional, modelo menos frecuente, define un sistema en el que ante una emergencia genéricamente descrita, todos los poderes del Estado son susceptibles de quedar concentrados en una magistratura única.

El estado excepcional constituye el modelo más característico del Derecho de excepción, y podemos definirlo como un sistema directamente regulado, basado en el mantenimiento sustancial del orden constitucional en situaciones de crisis, con la previsión de una serie de competencias extraordinarias definidas en la causa y en la actuación, que suponen la suspensión de la Constitución en alguno de sus extremos. El tipo de garantías que contempla la regulación de

${ }^{23}$ CRUZ VILLALÓN, P., Estados excepcionales y suspensión de garantías, op. cit.., p. 28.

${ }^{24}$ Como ejemplo de jurisprudencia constitucional italiana puede verse las Sentencias 123/1983 y la 100/1987, que han reconocido la necesidad de que en la declaración de situaciones de emergencia debe primar el principio de proporcionalidad como elemento de equilibrio entre las circunstancias desencadenantes de la emergencia y las medidas de excepción adoptadas.

${ }^{25}$ Op. cit., pp. 31 y ss. 
los estados excepcionales, aunque con matizaciones, suelen ser bastante similares: mecanismos de derogación del régimen de normalidad; su temporalidad, los mecanismos de control en sus distintas variantes y momentos, y, en todo Estado Democrático que se precie de serlo, prohibiciones tendentes a la defensa constitucional. Estos límites -lapso prefijado e imposibilidad de modificar la Constitución- son, junto con la inviolabilidad de los derechos humanos, características habituales de los actuales estados de excepción, de sitio o de conmoción, que están tutelados en la mayoría de las Constituciones democráticas del mundo.

\section{LOS ESTADOS DE EXCEPCIÓN EN EL DERECHO INTERNACIONAL DE LOS DERECHOS HUMANOS}

El estudio de las situaciones de emergencia y la protección de derechos en el Derecho Comparado, debe realizarse sobre la base, por un lado, del estudio de la normativa constitucional y legislativa existente en cada uno de los Estados y, en segundo lugar, atendiendo a la interesante tarea que realiza el orden internacional, puesto que no podemos obviar que a la hora de proceder al estudio comparado de los estados excepcionales, existe, como elemento común, el contenido de la normativa internacional sobre el tema, y en especial el art. $4 .^{\circ}$ del PIDCP; el art. 15 de la CEDH, y el art. 27 de la CADH de San José.

En cuanto al Derecho Internacional de los derechos humanos en sentido estricto, los Estados democráticos occidentales y latinoamericanos, han reconocido, casi en su totalidad, el Pacto de las Naciones Unidas sobre Derechos Civiles y Políticos suscritos en Nueva York el 16 de diciembre de 1966 (y un número importante de países de Latinoamérica, también ha suscrito el Protocolo Facultativo de dicho pacto). El artículo $4 .^{\circ}$. del Pacto regula los estados de excepción de la siguiente manera:

En situaciones excepcionales que pongan en peligro la vida de la nación y cuya existencia haya sido proclamado oficialmente, los Estados Parte en el presente Pacto podrán adoptar disposiciones que en la medida estrictamente limitada a las exigencias de la situación suspendan las obligaciones contraídas en virtud de este Pacto, siempre que tales disposiciones no sean incompatibles con las demás obligaciones que les imponga el derecho internacional y no entrañen discriminación alguna fundada únicamente en motivos de raza, color, sexo, idioma, religión u origen social. 2. La disposición precedente no autoriza suspensión de los artículos 6, 7, 8 (párrafos 1 y 2), 11, 15, 16 y 18). 3. Todo Estado Parte en el presente Pacto que haga uso del dere- 
cho de suspensión deberá informar inmediatamente a los demás Estados Partes en el presente Pacto, por conducto del Secretario General de las Naciones Unidas, de las disposiciones cuya aplicación haya suspendido y de los motivos que hayan suscitado la suspensión. Se hará una comunicación por el mismo conducto en la fecha en que ha dado por terminada la suspensión.

El Comité de Derechos Humanos de las Naciones Unidas establecido por el Protocolo Adicional al mencionado Pacto de Derechos Civiles y Políticos ha establecido una declaración general relativa al artículo 4. ${ }^{\circ}$ :

3. El Comité opina que las medidas adoptadas de conformidad con el artículo son de carácter excepcional y temporal y sólo pueden durar mientras corra peligro la vida la nación interesada, y que, en situaciones excepcionales es sumamente importante la protección de los derechos humanos, particularmente aquellos que no pueden ser objeto de suspensión. El Comité estima también que es igualmente importante que, en situaciones excepcionales, los Estados Partes informen a los demás Estados acerca de la índole y el alcance de la suspensión de derechos que hayan llevado a cabo, y la razones para ello y que cumplan, además, sus obligaciones de presentar informes de conformidad con el artículo 40 del Pacto, indicando la índole y medida de cada derecho suspendido, y que faciliten al mismo tiempo la documentación pertinente.

En relación con los citados derechos intangibles, los Instrumentos Internacionales de carácter general sobre derechos humanos hacen enumeraciones diversas, aunque coincidentes en varios aspectos, por ello resulta conveniente, para tener algún marco de referencia, mencionar otros dos preceptos que regulan dicha intangibilidad durante los estados de excepción. En primer término, el artículo 15, incisos 1 y 2 de la Convención Europea de Salvaguardia de los Derechos del Hombre y de las Libertades Fundamentales, suscrita en Roma el 4 de noviembre de 1950 y en vigor el 3 de septiembre de 1953, dispone:

En caso de guerra o en caso de otro peligro público que amenace la vida de la nación, cualquier alta parte contratante, puede tomar medidas que deroguen las obligaciones previstas en la presente Convención en la medida estricta en que lo exija la situación, y supuesto que tales providencias no sean opuestas a las otras obligaciones que dimanan del derecho internacional. 2. La disposición precedente no autoriza ninguna derogación del artículo $2 .^{\circ}$, salvo el caso de muertes resultantes de actos lícitos de guerra y a los artículos $3 .^{\circ}, 4 .^{\circ}$ (párrafo 2) y $7 .^{\circ}$.

El artículo 27 de la Convención Americana sobre Derechos Humanos, suscrita en la ciudad de San José, Costa Rica, el 22 de no- 
viembre de 1969, y en vigor desde el 18 de julio de 1978, es la más amplia en cuanto al señalamiento de derechos humanos inderogables en los estados de excepción, ya que dicho precepto establece:

1. En caso de guerra, de peligro público o de otra emergencia que amenace la independencia o segundad del Estado parte, éste podrá adoptar disposiciones que, en la medida y por el tiempo estrictamente limitados a las exigencias de la situación, suspendan las obligaciones contraídas en virtud de esta Convención, siempre que tales disposiciones no sean incompatibles con las demás obligaciones que le impone el derecho internacional y no entrañe discriminación alguna fundada en motivos de raza, color, sexo, idioma, religión u origen social.

2. La disposición precedente no autoriza la suspensión de los derechos determinados en los siguientes artículos: 3 (derecho al reconocimiento de la personalidad jurídica); 4 (derecho a la vida); 5 (derecho a la integridad personal); 6 (prohibición de esclavitud y servidumbre); 9 (principio de legalidad y de retro actividad); 12 (libertad de conciencia y de religión); 17 (protección a la familia); 18 (derecho al nombre); 19 (derechos del niño); 20 (derecho a la nacionalidad); 23 (derechos políticos); ni de las garantías judiciales indispensables para la protección de tales derechos.

En el ámbito internacional se han establecido una serie de requisitos de necesario cumplimiento para que la declaración de los estados de excepción sea considerada legal y legítima, tanto en los ámbitos nacional como internacional, requisitos que se convierten en principios respecto de los que, si bien no existe un criterio uniforme en la doctrina ${ }^{26}$ respecto a cuantos son, sí existe un relativo consenso al determinar los principales. Estos requisitos ayudan a determinar cuándo y de qué forma la declaratoria, vigencia y conductas tomadas por el Estado durante los estados de excepción atentan contra el Estado de Derecho y consecuentemente contra los derechos humanos. Dichos principios son:

- De forma:

a) Principio de Proclamación.

b) Principio de Notificación.

${ }^{26}$ GARCÍA SAYÁN identifica tres (proporcionalidad, razonabilidad, y temporalidad) Hábeas corpus y estados de emergencia. Segunda edición Comisión Andina de Juristas. Lima, 1988, pp. 21-25): O’DONELL considera un solo principio (necesidad) del cual derivan otros dos (proporcionalidad y temporalidad), Instrumentos para protección internacional de los Derechos Humanos. Segunda edición. Comisión Andina de Juristas, Lima, 1989,pp. 407-411). 
- De fondo:

a) Principio de Amenaza Excepcional.

b) Principio de Proporcionalidad. Las medidas de excepción «deben ser las requeridas para conjurar los peligros que se le presenten a la sociedad y al Estado. En consecuencia deben responder a la magnitud y características del fenómeno al que se quiere hacer frente ${ }^{27}$.

c) Principio de No Discriminación.

d) Principio de Temporalidad

e) Principio de Restablecimiento.

f) Principio de intangibilidad en la suspensión de derechos fundamentales expresamente indicados por las normas constitucionales e internacionales. Tal núcleo intangible está integrado por los derechos enunciados en los artículos 4.2 del Pacto Internacional y 27.2 del Pacto de San José28.

Los Convenios de la OIT sobre derechos humanos básicos contiene una serie de derechos referentes a cuestiones tales como el trabajo forzado, la libertad de asociación, la igualdad en el empleo y los derechos sindicales y de los trabajadores, que son complementarios al Pacto. Algunos de estos derechos no son susceptibles de derogación durante un estado de excepción; otros sí, pero sólo en la medida estrictamente necesaria para responder a las exigencias de la situación.

El Derecho Internacional Humanitario, también considera un núcleo intangible el Artículo 3, común a los cuatro Convenios de Ginebra. Su aplicación es obligatoria en cualquier tiempo y lugar, sobre todo cuando se reconoce la naturaleza excepcional del Derecho Internacional Humanitario.

g) Principio de Compatibilidad con otras Obligaciones Impuestas por el Derecho Internacional.

h) Principio de razonabilidad.

${ }^{27}$ GARCÍA SAYÁN, op. cit. 1988 , p. 22

${ }^{28}$ Para el sistema interamericano, tienen valor vinculante las opiniones Consultivas Nos. 8 y 9 de la Corte Interamericana de los Derechos Humanos, que en interpretación del Pacto de San José integra, a este núcleo intangible, tanto a los medios procesales para la protección de los derechos humanos, como a las garantías judiciales del debido proceso legal. 


\section{DEFENSA POLÍTICA DE LA CONSTITUCIÓN, DEMOCRACIA Y DERECHOS HUMANOS}

Si cuando hablamos de la defensa política de la Constitución, se está defendiendo la necesidad de superar problemas y crisis que pueden afectar el propio orden constitucional, el Estado de Derecho debe conllevar en su propia dialéctica la necesidad de un derecho de excepción, de manera que se prevea la excepcionalidad y se normativice la propia excepción, y así, la necesidad excepcional quede regulada y limitada por el Derecho. Pero las medidas de excepcionalidad, en el régimen constitucional democrático, han de estar suficientemente previstas y ser su aplicación muy rigurosa en el respeto al orden establecido.

No podemos olvidar que cuando se está en presencia de circunstancias que ponen en peligro el mantenimiento del orden establecido, ocasionando emergencia a todo o parte del país, es necesario tomar medidas de carácter excepcional. Dichas medidas se toman en el marco de la declaración de los estados excepcionales, en sus diversos tipos, pero pueden tentar al Estado a abusar del poder, lo que se puede traducir en transgresiones que derivan en violaciones de los derechos humanos, debido a que los mecanismos ordinarios de control quedan parcialmente suspendidos, dejando únicamente como elemento de control al diseño institucional. Para evitar estas tentaciones, es necesaria la existencia de mecanismos de control no sólo de carácter formal, sino también «informal» (como la población, los medios de comunicación y demás actores sociales y políticos), que puedan presionar para el mantenimiento del Estado de Derecho.

Las posibilidades constitucionales, una vez establecidas, llevan siempre a la tentación de utilizarlas. Aún más, tienden a inducir a las autoridades responsables a salir de situaciones difíciles o impopulares, echando mano de medidas excepcionales que no puedan ser justificadas ante el país. Tales consecuencias políticas y psicológicas difícilmente pueden evitarse, a menos que todos los elementos del Estado democrático permanezcan plenamente incorporados al mecanismo del gobierno de emergencia. El estado de excepción sigue siendo una tarea de cooperación democrática y de fe en la superioridad final de las sociedades libres con gobiernos responsables, más que un motivo para modificar constituciones y suspender las normas fundamentales de la democracia.

La regulación de formas seguras y eficaces de estados excepcionales debe hacerse desde el parámetro constitucional, al objeto de evi- 
tar tentaciones y sospechas de incompatibilidad con los sistemas democráticos. Y es que no podemos olvidar que los peligros y riesgos de abuso del derecho de excepción existen permanentemente, y en algunos casos tienen una plamación práctica. Así, no podemos obviar que existen supuestos en los que se dictan estados de emergencia como mecanismo para combatir la delincuencia común ${ }^{29}$. También recientemente hemos asistido a la declaración del estado de emergencia en Italia para luchar contra la inmigración clandestina, con lo que ello comporta para la garantía de los derechos humanos de los inmigrantes. Y por supuesto, no podemos olvidar las medidas adoptadas a raíz de los atentados del 11 de septiembre en EEUU.

Tras los dramáticos sucesos del 11 de septiembre, muchas de las más representativas democracias han adoptado una serie de medidas que, bajo el manto de la «seguridad», están socavando las bases del Estado de Derecho. De manera inusitadamente rápida, ha surgido todo un abanico de poderes de emergencia basados en el concepto de excepciones y que tienen por finalidad poner a disposición de los poderes políticos un marco legislativo que les permita actuar al margen de las instituciones constitucionales y representativas ordinarias. Con ello, se haría, en parte, realidad la idea de CARL SCHMITT, gran teórico de la excepción, y que la entendía como el poder que tiene el soberano para tomar decisiones en función de sus deseos e intereses políticos, en lugar de verse supeditado al derecho normativo.

${ }^{29}$ Ya en su Informe Anual de 1998, la Comisión Interamericana de Derechos Humanos criticó que «combatir la delincuencia mediante la suspensión de garantías individuales, en virtud del estado de emergencia, no se ajusta a los parámetros exigidos por la Convención Americana para que sea procedente su declaración» y que el Estado «tiene y debe contar con otros mecanismos para canalizar el malestar social y combatir la delincuencia que no signifiquen la derogación de garantías esenciales de la población». Más reciente y precisa, en julio de 2007, la Corte Interamericana de Derechos Humanos en el último caso que sentenció contra Ecuador, el Caso Zambrano Vélez y otros (4-julio 2007)(que se refiere a la ejecución extrajudicial de tres personas por parte de la fuerza pública con ocasión de un estado de emergencia que Durán-Ballén declaró en 1993) estimó «absolutamente necesario enfatizar el extremo cuidado que los Estados deben observar al utilizar las Fuerzas Armadas como elemento de control de la protesta social, disturbios internos, situaciones excepcionales y criminalidad común» y citó su jurisprudencia del Caso Montero Aranguren y otros (Retén de Catia) (5 julio 2006) en la que con suma sensatez consideró que «los estados deben limitar al máximo el uso de las Fuerzas Armadas para el control de disturbios internos, puesto que el entrenamiento que reciben está dirigido a derrotar al enemigo, y no a la protección y control de civiles, entrenamiento que es propio de los entes policiales». Straka, Úrsula., «Estados de excepción y problemas de agencia», en Politeia v. 28 n. 28 Caracas ene. 2002. 
En EEUU, el 11 de septiembre no ha sido otra cosa que el detonante para suspender, primeramente de forma temporal y después definitivamente, numerosas libertades públicas e individuales.

La renovación de la Patriot Act ha permitido otorgar un carácter duradero a una serie de medidas que, en el momento de su adopción en 2001, fueron presentadas como la necesaria respuesta a una situación de urgencia. Las medidas de excepción que tomó el gobierno estadounidense, tras los atentados del 11 de septiembre de 2001, se basan en el voto del Congreso que estipula «que el Presidente está autorizado a utilizar toda la fuerza necesaria y apropiada contra las naciones, organizaciones o personas que planificaron, autorizaron, cometieron o ayudaron a cometer los atentados terroristas ocurridos el 11 de septiembre de 2001.

La Patriot Act de 13 de noviembre autoriza, entre otras medidas, la encarcelación, sin juicio ni presentación de cargos y por tiempo indeterminado, de extranjeros sospechosos de terrorismo, así como la instauración de una vigilancia generalizado sobre la población, y el procesamiento por «military comissions» —que no hay que confundir con los tribunales militares para tiempos de guerra. Algunas de estas medidas de control son de carácter permanente. Otras fueron aprobadas por votación para un período de 4 años. Estas últimas, enumeradas en 16 artículos, expiraban a finales de 2005 (La Patriot Act Reauthorization). El proceso de renovación de la Patriot Act también permitió prolongar por 4 años más la sección 6001 de la Intelligence Reform and Terrorism Prevention Act de 2004, que autoriza la vigilancia de personas aisladas, sospechosas de ser terroristas.

En este contexto, la emergencia de ciertos aspectos de los estados de excepción debiera ser motivo de preocupación en la defensa de los derechos fundamentales.

La defensa del Estado de Derecho mediante el uso de estados de excepción nos obliga a respetar los derechos humanos y a utilizar una filosofía de defensa de los derechos humanos para afrontar las situaciones de excepción. El respeto de los derechos humanos es un elemento fundamental para la consolidación del Estado de Derecho, y este respeto se puede ver afectado cuando existe una declaratoria de estados de excepción que exacerba los problemas existentes entre el Estado, los órganos ejecutores, los supervisores y los ciudadanos, pudiendo traducirse en un aumento de la posibilidad de violación a los derechos humanos.

El pronunciamiento del Alto Comisionado de las Naciones Unidas para los Derechos Humanos «Desafío de los derechos humanos en el 
marco de los estados de excepción ${ }^{30}$ reconoce el derecho-deber de todos los Estados de combatir los actos terroristas y la violencia armada para garantizar su propia seguridad, pero esta potestad deberá hacerse en el marco del respeto de la legalidad, de los derechos humanos y del Estado democrático de Derecho. Debe existir un justo equilibrio entre el goce de las libertades individuales y el interés general en torno a la seguridad nacional, puesto que en democracia, el poder no puede ejercerse sin límite alguno, ni el Estado puede valerse de cualquier procedimiento para alcanzar sus objetivos.

La suspensión de garantías constituye una situación excepcional, en virtud de la cual un Estado puede lícitamente aplicar determinadas medidas restrictivas a los derechos y libertades de las personas, que en condiciones normales, están prohibidas o sometidas a requisitos más rigurosos. Por el contrario, resulta ilegal toda actuación del Estado que desborde los alcances y límites que deben estar precisados en las disposiciones que decretan el estado de excepción.

El Derecho Internacional de los Derechos Humanos permite la suspensión del ejercicio de ciertos derechos en situaciones de emergencias, pero estableciendo cuáles son los requisitos para que un Estado pueda proceder a su suspensión.

En primer lugar, sólo podrán ser objeto de suspensión en situaciones de emergencia aquellos derechos y libertades que están contemplados, a nivel internacional, en el art. 4 del Pacto Internacional de Derechos Civiles y Políticos; a nivel americano en el art. 27 de la Convención Americana sobre Derechos Humanos, y a nivel europeo, en el art. 15 del Convenio para la Protección de los Derechos Humanos y de las Libertades Fundamentales.

Además, hay que tomar en consideración que existe un núcleo de derechos y libertades cuya suspensión no puede hacerse bajo el amparo de situaciones de emergencia.

Así, el PIDCyP, en su art. 4.2 no autoriza la suspensión del derecho a la vida; la prohibición de la tortura; la prohibición de la esclavitud y de la servidumbre; la prohibición del encarcelamiento por incumplimiento de obligaciones contractuales; el principio de legalidad e irretroactividad de la ley penal; el reconocimiento de la personalidad jurídica y la libertad de pensamiento, de conciencia y de religión.

${ }^{30}$ Oficina del Alto Comisionado de las Naciones Unidas para los Derechos Humanos. 25 de septiembre de 2002. 
Por su parte, el art. 15. 2 del Convenio Europeo de Derechos Humanos no autoriza ninguna derogación del derecho a la vida, salvo para el caso de muertes resultantes de actos lícitos de guerra; la prohibición de la tortura; la prohibición de la esclavitud y de la servidumbre; y el principio de legalidad e irretroactividad de la ley penal.

Dentro del Sistema Americano, el art. 27.2 de la CADH prohíbe la suspensión del derecho al reconocimiento de la personalidad jurídica; el derecho a la vida; el derecho a la integridad personal; la prohibición de la esclavitud y servidumbre; el principio de legalidad y de retroactividad; la libertad de conciencia y de religión; la protección a la familia; el derecho al nombre; los derechos del niño; el derecho a la nacionalidad; los derechos políticos; como así también prohíbe la suspensión de las garantías judiciales indispensables para la protección de tales derechos ${ }^{31}$.

La Observación General N. ${ }^{\circ}$ 29, distingue dos situaciones, que también son abordadas en el Pronunciamiento del Alto Comisionado de las Naciones Unidas para los Derechos Humanos: 1) Las limitaciones o restricciones permitidas aún en circunstancias o situaciones normales, conforme a diversas disposiciones del Pacto; y 2) La suspensión de algunas de las obligaciones contraídas por los Estados Partes en virtud del PIDCyP en situaciones de excepción. Así, queda plasmado que la permisibilidad de ciertas restricciones es independiente de la cuestión de la suspensión.

El PIDCyP y otros Instrumentos Internacionales sobre la materia, contemplan la limitación de ciertos derechos fundamentales, pero esta limitación, en primer lugar, tienen que estar previstas por una ley formal previa, adoptada por el órgano legislativo, según el procedimiento interno de cada Estado Parte. Además, esas limitaciones deben ser estrictamente necesarias en una sociedad democrática; no deben comportar la supresión del derecho mismo; deben ser

${ }^{31}$ El Pacto de San José de Costa Rica contiene un catálogo de derechos que no pueden suspenderse, más extenso que los demás tratados de protección de derechos humanos, y constituye el primer instrumento internacional de derechos humanos que prohíbe expresamente la suspensión de las «garantías judiciales indispensables» para la protección de los derechos que no pueden ser suspendidos y para su efectiva exigibilidad en sede judicial.

La necesidad de determinar cuáles son esas garantías judiciales, llevó a la Corte Interamericana de Derechos Humanos a pronunciarse en dos Opiniones Consultivas, como así también al Alto Comisionado de Naciones Unidas en el pronunciamiento mencionado supra y al Comité de Derechos Humanos en su Observación General N. ${ }^{\circ} 29$. 
proporcionadas a las circunstancias específicas y ser compatibles con el objeto y fin del Pacto y con los principios de legalidad y del estado democrático de derecho. Es decir, las limitaciones a ciertos derechos deben ser necesarias para proteger la seguridad nacional, el orden público, la salud o la moral públicas o los derechos y libertades de terceros.

Toda suspensión de derechos, por su parte, debe estar supeditada a los siguientes requisitos:

1. Que las situaciones excepcionales pongan en peligro la vida de la nación o que amenacen la independencia o seguridad del Estado. Las medidas adoptadas deben ser, en primer lugar, excepcionales. No todo disturbio o catástrofe constituye una situación excepcional que ponga en peligro la vida de la nación. Incluso en un conflicto armado las disposiciones que suspendan la aplicación del Pacto se permitirán sólo en la medida en que la situación constituya un peligro para la vida de la nación. Cuando los Estados Partes consideren la posibilidad de invocar el artículo 4 en situaciones distintas de un conflicto armado, deberán ponderar cuidadosamente el motivo por el cual esa medida es necesaria y legítima en las circunstancias del caso. En varias ocasiones, el Comité ha expresado su preocupación en relación con algunos Estados Partes que parecen haber suspendido la vigencia de los derechos protegidos por el Pacto, o cuyo derecho interno parece permitir esa suspensión en situaciones no contempladas en el artículo $4^{32}$.

2. Que la existencia de la situación excepcional haya sido proclamada oficialmente por el Gobierno del Estado Parte respectivo.

3. Que las medidas adoptadas sean temporales. Este requisito guarda relaciones con la duración, el ámbito geográfico y el alcance material del estado de excepción y de cualesquiera disposiciones excepcionales aplicadas en razón de la emergencia. La suspensión de algunas de las obligaciones contraídas en virtud del Pacto en situaciones de excepción es claramente distinta de las restricciones o limitaciones permitidas aun en circunstancias normales conforme a

32 Véanse las siguientes observaciones finales: República Unida de Tanzanía (1992), CCPR/C/79/Add. 12, párr. 7; República Dominicana (1993), CCPR/C/79/Add.18, párr. 4; Reino Unido de Gran Bretaña e Irlanda del Norte (1995), CCPR/C/79/Add. 55, párr. 23; Perú (1996), CCPR/C/79/Add. 67, párr. 11; Bolivia (1997), CCPR/C/79/Add.74, párr. 14; Colombia (1997), CCPR/C/79/Add. 76, párr. 25; Líbano (1997), CCPR/C/79/Add. 78, párr. 10; Uruguay (1998), CCPR/C/79/Add. 90, párr. 8; Israel (1998), CCPR/C/79/Add. 93, párr. 11. 
diversas disposiciones del Pacto. Sin embargo, la obligación de limitar cualesquiera suspensiones a las estrictamente necesarias según las exigencias de la situación refleja un principio de proporcionalidad común a las facultades de suspensión y de limitación ${ }^{33}$.

4. Que el hecho de que algunos derechos y libertades reconocidos por el PIDCyP estén enunciados en el art. 4 del mismo instrumento legal como derechos que no se suspenden, no significa que otros derechos no enunciados puedan ser suspendidos discrecionalmente, lo que conlleva la obligación de cada Estado Parte de proceder a un análisis minucioso de cada derecho reconocido, sobre la base de una evaluación objetiva de la situación de hecho de que se trate ${ }^{34}$.

5. Que las medidas que suspendan obligaciones contraídas en virtud del Pacto no sean incompatibles con otras obligaciones que dimanan del Derecho Internacional, especialmente, el Derecho Internacional Humanitario. Así, durante un conflicto armado, son aplicables las disposiciones del Derecho Humanitario en forma complementaria a las disposiciones del art. 4 para impedir el abuso de las facultades excepcionales del Estado. Las aproximaciones y convergencias entre el Derecho Internacional de los Derechos Humanos y el Derecho Internacional Humanitario en los planos normativo, hermeneútico y operativo aseguran un amplio alcance de la protección de los derechos humanos durante los estados de excepción - es precisamente en los estados de excepción cuando se evidencia con mayor

${ }^{33} \mathrm{Al}$ examinar los informes de los Estados Partes, el Comité ha expresado su preocupación por el hecho de que no se presta suficiente atención al principio de proporcionalidad. Véanse, por ejemplo, las observaciones finales sobre Israel (1998), CCPR/C/79/Add. 93, parr. 11.

${ }^{34}$ En su Opinión Consultiva 08/87, del 30 de enero de 1987, la Corte Interamericana de Derechos Humanos se pronuncia, en virtud de la competencia ratione materiae prevista por el art. 64.1 de la CADH, sobre una pregunta formulada por la Comisión Interamericana de Derechos Humanos, respecto a si el recurso de hábeas corpus, cuyo fundamento jurídico se encuentra en los artículos 7.6 y 25.1 de la CADH, es una de las garantías judiciales que, de acuerdo al artículo 27 de esa Convención no pueden suspenderse por un Estado Parte de la Convención Americana.

La Corte sostiene que la interpretación de los artículos 25.1 y 7.6 de la CADH con respecto a la posibilidad de suspender el hábeas corpus en los estados de excepción, frente a lo dispuesto en el artículo 27.2, debe hacerse utilizando las normas de la Convención de Viena sobre el Derecho de los Tratados, que pueden considerarse reglas de derecho internacional general sobre el tema, de acuerdo con las cuales «un tratado deberá interpretarse de buena fe conforme al sentido corriente que haya de atribuirse a los términos del tratado en el contexto de éstos y teniendo en cuenta su objeto y fin» y la necesidad de evitar «suprimir el goce o ejercicio de los derechos y libertades reconocidos en la Convención o a limitarlos en mayor medida que la prevista en ella». 
intensidad la complementariedad de ambas ramas del Derecho Internacional-.

Desde la perspectiva del DIH son relevantes el artículo 3 común a los Convenios de Ginebra y las disposiciones del Protocolo II que establecen obligaciones para las partes en conflicto (Estado y los actores no estatales). De este modo se constata la necesidad de aplicar complementariamente los artículos 4.2 del PIDCP, 27.2 de la CADH y 3 común a los Convenios de Ginebra.

En el ámbito del Derecho Internacional Humanitario es relevante recordar la Declaración de Estándares Mínimos Humanitarios de Turku Abo de 1990, que en aplicación del Derecho Internacional de los Derechos humanos y del Derecho Internacional Humanitario establece que ciertos derechos no admiten restricciones dado que no es admisible cualquier tipo de derogación de derechos en base a una emergencia pública. Las situaciones de excepción, realzan el amplio alcance de las obligaciones convencionales, y la importancia de la protección erga omnes de determinados derechos básicos de la persona humana. Las garantías mínimas de esos derechos, consagradas en el derecho internacional humanitario y en la protección internacional de los derechos humanos han de ser tomadas en conjunto» ${ }^{35}$.

Los Estados Partes no pueden en ningún caso invocar el artículo 4 del Pacto como justificación de actos que violan el derecho humanitario o normas imperativas de derecho internacional.

El propio art. 5 del PIDCyP prohíbe la restricción o menoscabo de ninguno de los derechos humanos fundamentales reconocidos en otros instrumentos bajo pretexto de que el Pacto no los reconoce o los reconoce en menor grado. Por consiguiente, al invocar el párrafo 1 del artículo 4, o al informar sobre el marco jurídico que rige las situaciones de excepción en los informes previstos en el artículo 40, los Estados Partes deben presentar información acerca de otras obligaciones internacionales que les incumban y que guarden relación con la protección de los derechos de que se trate, en particular las obligaciones vigentes en períodos de excepción ${ }^{36}$. A este respecto, los Es-

${ }^{35}$ CANÇADO TRINDADE, A., «Desarrollo de las Relaciones entre el Derecho Internacional Humanitario y la Protección Internacional de los Derechos Humanos», en: Revista IIDH 6, Instituto Interamericano de Derechos Humanos, julio-diciembre de 1992, San José, p. 67.

${ }^{36}$ Se hace referencia a la Convención sobre los Derechos del Niño, que ha sido ratificada por casi todos los Estados Partes en el Pacto y no contiene ninguna cláusula 
tados Partes deben tener debidamente en cuenta la evolución del Derecho internacional en cuanto a las normas de derechos humanos aplicables en situaciones de excepción ${ }^{37}$.

6. Que las medidas adoptadas no entrañen discriminación alguna fundada en motivos de raza, color, sexo, idioma, religión u origen social. Si bien las disposiciones contenidas en el Pacto referidas a la prohibición de la discriminación no figuran entre las disposiciones que no pueden ser suspendidas, el derecho a la no discriminación no admite excepción en circunstancia alguna.

7. Que se comunique a los demás Estados, por conducto del Secretario General de la ONU, OEA o Consejo de Europa, información detallada sobre las disposiciones cuya aplicación haya suspendido; una clara explicación de los motivos que hayan suscitado la suspensión y la fecha en que haya dado por terminada tal suspensión.

En definitiva, las garantías relacionadas con la institución de la suspensión en las situaciones excepcionales, se basan en los principios de legalidad y del Estado de Derecho.

En conclusión, la suspensión de garantías, en aplicación del Derecho de excepción, debe ser compatible con la forma democrática de gobierno. Los sistemas jurídicos, por lo general, permiten la adopción de medidas excepcionales para actuar en situaciones de

de suspensión. Como lo señala claramente el artículo 38 de esa Convención, su texto es aplicable en situaciones de excepción.

${ }^{37}$ Se hace referencia a los informes del Secretario General a la Comisión de Derechos Humanos presentados de conformidad con las resoluciones 1998/29, 1999/65 y 2000/69 de la Comisión sobre normas humanitarias mínimas (posteriormente: normas fundamentales de humanidad), E/CN.4/1999/92, E/CN.4/2000/94 y E/CN.4/2001/91, y a los esfuerzos hechos para determinar los derechos fundamentales vigentes en toda circunstancia, por ejemplo, los Principios mínimos de las normas relativas a los derechos humanos en los estados de excepción, aprobados en París (Asociación de Derecho Internacional, 1984); los Principios de Siracusa sobre la limitación o suspensión de disposiciones del Pacto Internacional de Derechos Civiles y Políticos, el informe final del Sr. Leandro Despouy, Relator Especial de la Subcomisión sobre los derechos humanos y los estados de excepción (E/CN.4/Sub.2/1997/19 y Add.1); los Principios rectores de los desplazamientos internos (E/CN.4/1998/53/Add. 2); y la Declaración de Normas Humanitarias Mínimas de Turku (Åbo), de 1990 (E/CN.4/1995/116). En lo que respecta a otros trabajos en curso sobre este tema, también se hace referencia a la decisión adoptada en la 26. ${ }^{\text {a }}$ Conferencia Internacional de la Cruz Roja y la Media Luna Roja (1995) por la que se asigna al Comité Internacional de la Cruz Roja la tarea de preparar un informe sobre las normas consuetudinarias del derecho internacional humanitario aplicable en situaciones de conflicto armado internacional y no internacional. 
emergencia, sin embargo la adopción de dichas medidas y su impacto en el goce de los derechos humanos debe estar regulada estrictamente. El Derecho Internacional reviste la mayor importancia para el sistema de protección de los derechos humanos. Por una parte, autoriza a los Estados Partes a suspender unilateralmente y temporalmente algunas de las obligaciones que les incumben en virtud del Pacto, por otra, somete tanto la adopción misma de la medida de suspensión, así como sus consecuencias materiales, a un régimen específico de salvaguardias: el restablecimiento de un estado de normalidad, en que se pueda asegurar de nuevo el pleno respeto $^{38}$. Sin embargo, las medidas de suspensión que se adopten en casos excepcionales dependen «del carácter, intensidad, profundidad y particular contexto de la emergencia, así como de la proporcionalidad y razonabilidad que guarden las medidas adoptadas respecto de ella ${ }^{39}{ }_{\text {» }}$ sin que ellas comporten la suspensión temporal del Estado de Derecho o autoricen al gobierno a amparar su conducta en el campo de la ilegalidad. Ello por cuanto, «el principio de legalidad, las instituciones democráticas y el Estado de Derecho son inseparables... En una sociedad democrática los derechos y libertades inherentes a la persona, sus garantías y el Estado de Derecho constituyen una tríada, cada uno de cuyos componentes se define, completa y adquiere sentido en función de los otros ${ }^{40}$ ».

El Derecho de los derechos humanos proporciona equilibrios para proteger el disfrute de los derechos durante los estados de excepción al tiempo que permite la derogación de algunos de estos derechos en situaciones concretas. Estas salvaguardas se reflejan en diversos instrumentos de Derecho Internacional, que se complementan con el Derecho Internacional Humanitario que se convierte en un instrumento de suma relevancia, puesto que contiene normas para la protección de los derechos humanos durante las situaciones de crisis.

La Convención Americana sobre Derechos Humanos, el Pacto Internacional de Derechos Civiles y Políticos, y el Convenio Europeo de Derechos Humanos, contienen un catálogo de los derechos que no pueden suspenderse «en caso de guerra, peligro público u otra emer-

${ }^{38}$ Observación general sobre el artículo 4, en caso de «Estados de emergencia» (adoptada el 24 de julio de 2001 durante la 1950. ${ }^{\text {a }}$ reunión), que reemplaza a su Observación general N. 5 aprobada en el $13 .^{\circ}$ período de sesiones, en 1981.

${ }^{39}$ Corte Interamericana de Derechos Humanos. Opinión Consultiva OC-8/87 del 30 de enero de 1987, párr. 22.

${ }^{40}$ OC N. ${ }^{\circ} 08 / 87$, op. cit., párr. 24 y 26. 
gencia». Existen ciertos derechos y libertades contenidos en los distintos instrumentos de protección de derechos humanos que no pueden ser suspendidos ni aún en estados de excepción, por constituir los mismos normas imperativas o de «ius cogens», de conformidad a las disposiciones de Derecho Internacional contenidas en el art. 53 de la Convención de Viena sobre Derechos de los Tratados. 